\title{
SAÚDE E SEGURANÇA NO TRABALHO EM POSTO DE COMBUSTÍVEL
}

\author{
HEALTH AND SAFETY AT WORK IN FUEL \\ Jonas Gomes Ferreira - jonas-ccb2011@ hotmail.com \\ Daniela Rodolpho - danirodolpho@yahoo.com.br \\ Faculdade de Tecnologia de Taquaritinga (FATEC) - SP - Brasil
}

DOI: 10.31510/infa.v15i2.488

\begin{abstract}
RESUMO
É notável que as empresas vêm sendo modernizadas em questões de segurança no trabalho, no entanto em postos de combustíveis esse risco é eminente, pois o frentista tem diversas funções na sua jornada de trabalho que leva o alto fator de lesões a saúde, mas isso vem sendo questionado através de trabalhos e pesquisas no qual já demonstraram numerosos índices de malfeitoria principalmente relacionado ao agente químico benzeno, o que levou a corte de alguns hábitos e inserindo os EPIs relacionados diretamente pra esse setor trabalhista o que tem ajudado em questões de prevenção, porém nem todas podem ser inibidas e sim evitadas e amenizadas como mostra nesse trabalho. Ao termino dessa pesquisa bibliográfica descobrimos que além dos empregadores investir na saúde e segurança do trabalhador, o próprio empregado deve se conscientizar e buscar melhorias voltadas para sua própria saúde pois, devido ao risco que ele corre, é grande os números de doenças que pode tornar seu futuro preocupante.
\end{abstract}

Palavras-chave: Saúde. Segurança. Benzeno.

\begin{abstract}
It is notable that companies have been modernized in matters of safety at work, however at gas stations this risk is eminent, as the franchisee has several functions in his workday that carries the high factor of health injuries, but this comes being questioned through work and research in which they have already demonstrated numerous indices of malfeasance mainly related to the benzene chemical agent, which led to the cutting of some habits and inserting the PPE related directly to this labor sector which has helped in prevention issues, not all can be inhibited but avoided and mitigated as shown in this work. At the end of this bibliographical research we find that in addition to the employers investing in the health and safety of the worker, the employee himself must be aware of and seek improvements aimed at his own health because due to the risk he runs, the numbers of diseases that can make his worrying future.
\end{abstract}

Keywords: Health. Security. Benzene. 


\title{
1 INTRODUÇÃO
}

Nesse projeto será discutido sobre a qualidade de vida no trabalho, satisfação dos trabalhadores, aumento da produtividade quando o empregador decide investir na saúde e segurança do funcionário e sobre o benzeno que faz tanto mal a saúde do colaborador, visto que a segurança do empregado é fundamental para o exercício de seu trabalho.

Para tal discussão, será utilizado como base revisões bibliográficas que justifiquem a importância do trabalhador para a empresa. Como nos apresenta David e Faria (2011 apud MAIA, 2010) quando menciona que a partir das décadas de 60 e 70, o trabalhador passou a ser visto como cidadão no trabalho. Desse modo, os trabalhadores passam a ter voz ativa quando o assunto é direito do trabalho, visando a cidadania.

Com isso, esse trabalho busca estudar e abordar sobre a qualidade de vida dos frentistas de postos de abastecimento de combustíveis, o qual parece ser um serviço simples, mas não o é, pois os frentistas estão expostos ao público e exige exercício físico e mental. Apresentando também a necessidade dos Equipamentos de Proteção Individual (EPIs), como máscaras, aventais, luvas, camisetas de mangas longas em determinada atividade em que for exercer.

\section{FUNDAMENTAÇÃO TEÓRICA}

\subsection{Qualidade de vida no trabalho}

\begin{abstract}
A qualidade de vida no trabalho é uma forma de pensamento envolvendo indivíduo, organização e trabalho, mas, ainda não existe um consenso sobre a abrangência de sua abordagem. Embora a temática da qualidade de vida no trabalho tenha recebido considerável atenção nestas duas últimas décadas, ainda existe alguma incerteza com relação ao sentido exato do termo. (MAIA; MAIA, 2010, p. 4).
\end{abstract}

A partir da década de 50 a qualidade de vida no trabalho é estudada, principalmente no que se refere a satisfação do trabalhador com a organização e com a tarefa que é executada.

O local de trabalho de postos de abastecimento de combustíveis é um ambiente de trabalho onde se encontra diversos riscos á saúde dos funcionários, produtos químicos, movimentos repetitivos, riscos de assaltos, atropelamentos dentre outros.

Um aspecto muito importante a ser estudado, sobre a qualidade de vida no trabalho é a ergonomia, pois no trabalho de frentista exige muitos movimentos rápidos e repetitivos. 


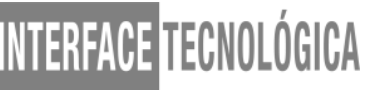

Também deve ser estudado sobre ergonomia franco fônica que segundo Ferreira e Freire (2001) consiste na centralização de análises de situações reais de atendimento, onde podem ser identificados aspectos mais profundos que causam não apenas problemas físicos mais evoluem para desgaste psicológico devido à pressão mental.

Segundo Albuquerque e França (1998) a qualidade de vida no trabalho é um conjunto de ações de uma empresa que envolve inovações e melhorias dentro e fora do local de trabalho, visando melhorar condições plenas de desenvolvimento humano durante ou não a realização do trabalho.

É importante, de acordo com Fernandes e Gutierrez (1988, p.4) referir-se ainda a esforços no sentido de melhorar a situação do trabalho, buscando soluções mais adequadas que visem à reformulação e condições negativas dos cargos, tornando a empresa mais produtiva e os colaboradores mais satisfeitos.

\subsection{Equipamentos de Proteção Individual}

O ambiente de trabalho nos postos de revenda de combustíveis é um local onde os funcionários passam por numerosos riscos, por isso há necessidade do uso de Equipamentos de Proteção Individual (EPIs).

Uma análise recente ainda não publicada, feita pelo Estado de Santa Catarina garante efeitos desse estudo e comprova uma decomposição entre o oficio nos postos de combustíveis e o uso de EPIs (D'ALASCIO et al., 2014).

No demonstrativo do mesmo autor, um grande número de trabalhadores não receberam instruções sobre reconhecimento, avaliação e controle de exposição a agentes tóxicos.

Nessa circunstancia nasce a obrigação de identificar a efetiva veracidade dos trabalhadores frentistas e relacionados, de modo que ajude com as medidas estratégicas de intervenção no qual possibilite a vitalidade a prevenção de riscos e danos resultantes do ambiente de trabalho.

Para tal fato, Rocha et al. (2014) elaborou a seguinte questão: quais os equipamentos de proteção individual utilizados pelos atendentes frentistas de postos de combustíveis no ambiente de trabalho? 


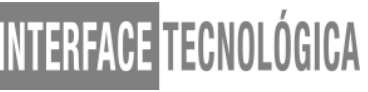

O propósito é identificar quais equipamentos de proteção seriam destinados obrigatoriamente para esse setor trabalhista sendo que todos os setores têm uma necessidade diferente de equipamento.

De acordo com Guaporé (2018), existem 4 funções dos frentistas:

1. Limpeza do posto

Os trabalhadores encarregados pela limpeza de válvulas, bombas e seus compartimentos de contenção de vazamentos, caixas de passagem e canaletas devem usar mascaras respiratórias, luvas impermeáveis e sapatos adequados.

\section{2. $\quad$ Frentista}

Devem usar uniformes que são fornecidos pela empresa e calçados adequados

Para a limpeza de superfícies contaminadas com benzeno e sua composição, como por exemplo, respingos de combustíveis durante o abastecimento devem utilizar luvas impermeáveis e toalhas de papel.

\section{Lubrificação}

Trata-se da troca de óleo e filtros relacionados ao motor do veiculo.

Para isso é necessário alguma proteção na mão para evitar contato do óleo com a pele, para isso existe luvas, cremes protetores e aventais.

4. Abastecimento de tanques

Nessa atividade o funcionário deve descarregar o combustível dos caminhões transportadores para o tanque de armazenamento do posto, há grande risco de contato com benzeno por vias aéreas respiratórias e oculares, por isso devem utilizar proteção respiratória de face inteira, com filtros recomendados por norma e equipamentos de proteção para a pele abaixo segue imagens de alguns itens de proteção específicos para funções de contato direto com combustíveis.

$\mathrm{O}$ uso desses equipamentos traz segurança e ameniza muitos riscos que os trabalhadores passam, levando em conta que é de baixo custo para os empregadores e é um investimento que trará benefícios para a empresa, assim estará evitando acidentes que poderia acarretar atestados médicos, afastamentos por lesões, invalidez ou até mesmo a morte do empregado. 


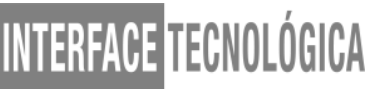

\subsection{O trabalho do frentista}

Todo posto de gasolina, além de seu administrador, necessita dos frentistas, os quais têm a função de atender ao público, acompanhar o recebimento de combustíveis, relatar possíveis problemas a ocorrerem no local de trabalho, dentre outros serviços que lhes são propostos.

Como o frentista está em contato direto com produtos químicos, o mesmo deve fazer uso de equipamentos de proteção, os quais foram citados no capítulo 2.2. Além disso, o frentista deve cumprir uma carga horária de 7horas e 20minutos, com 40minutos de descanso, devido ao trabalho insalubre.

"A carga de trabalho [...] é definida pela interrelação entre as exigências externas, ambientais, instrumentais, organizacionais, impostas ao operador.” (FERREIRA; FREIRE, 2001).

O trabalho dos frentistas é um serviço de atendimento ao público, o mesmo contracenam com diversos tipos de pessoas, onde os elementos de cenografia aparecem definidos a priori pela empresa (equipamentos, instrumentos, espaço), e as regras da interação dos sujeitos são preestabelecidas pela organização do trabalho (FERREIRA, 1999 apud FERREIRA; FREIRE, 2001).

De acordo com Ferreira, (200_ apud FERREIRA; FREIRE, 2001) as linhas gerais da abordagem teórica em ergonomia do serviço de atendimento, foram objeto de análise, devido ao atendimento ao público ser uma atividade complexa e mediadora, que deve ser usada a interação social, visando atender todas as necessidades distintas.

Sobretudo olhando para o trabalho dos frentistas não enxergamos os diversos serviços o qual eles exercem, mas há a existência de múltiplas funções.

\footnotetext{
Nesse sentido, a concepção formal da organização ambiciona um funcionário que desempenhe distintos papéis, que transcendem de longe o senso comum do frentista como "alguém que apenas executa o abastecimento de combustível". (FERREIRA; FREIRE, 2001).
}

Segundo Ferreira e Freire (2001), a jornada de trabalho dos frentistas compreende essencialmente três momentos distintos: Início da jornada, atividades de atendimento aos clientes, e encerramento da jornada. A atividade de atendimento aos clientes pode ser resumida nos seguintes tipos de ação:

abordagem do cliente, solicitando informações sobre o serviço desejado; 


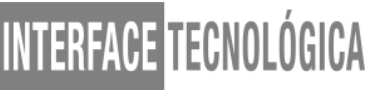

zeramento da bomba e acionamento do mecanismo de abastecimento automático da bomba;

$>$ consulta ao cliente para saber se ele deseja a realização dos serviços de limpeza do pára-brisa e faróis do veículo;

$>$ retirada da mangueira da bomba, após alarme acionado automaticamente, indicando a conclusão do abastecimento;

$>$ informação ao cliente e recebimento do valor do produto, que pode ser feito em diversas formas de pagamento: dinheiro, cheque, cartão de debito e/ou crédito ou marcar na conta do cliente se ele tiver conta no posto;

$>$ execução de procedimentos administrativos específicos em função da modalidade de pagamento escolhida pelo cliente;

$>$ fechamento do caixa, no caso dos frentistas que operam o caixa.

No entanto o trabalho dos frentistas, confirmando uma inferência na análise do trabalho prescrito, não se encontra apenas como o papel de um vendedor, mas predominante na função de caixa. Durante o tempo de trabalho os frentistas passam a maior parte do tempo executando tarefas de recebimento, deposito, contabilizando o caixa, limpeza, trocando óleo. A importância dessas atividades se fundamentam, sobretudo, nos riscos que eles possam está correndo.

\subsection{A prevenção dos frentistas contra acidentes e doenças}

As instituições de PRCV (Posto de Revenda de Combustíveis no Varejo) informam que são precisas estratégicas que proíbem e inibem tais práticas que podem ser prejudicial ao seu desempenho, tal como cheirar a tampa de combustível, um hábito rotineiro para deduzir o combustível utilizado, que é um hábito desnecessário, pois o colaborador pode apenas perguntar ao condutor qual combustível será usado em seu veículo.

Com o surgimento das bombas automatizadas, não há inevitabilidade de aproximar a face do rosto no tanque de combustível com o intuito de observar se o mesmo está enchendo e também inalar o vapor do mesmo pelo simples fato de as bombas padronizadas de acordo com as normas obterem válvula automática para desarme da mesma para evitar tais danos ao empregado.

Segundo Johnson e Morata (2010), as investigações toxicológicas na área de neurologia e otoneurologia mostram a ação dos solventes orgânicos no sistema auditivo. A 
razão principal é que esses produtos orgânicos são caracterizados por alta volatilidade e lipossolubilidade, o que facilita sua absorção nos tecidos e sua ligação aos lipídios. E a perda auditiva induzida por exposição a produtos químicos, na maioria das vezes, é de grau moderado a severo.

\subsection{O Benzeno como malefício à saúde}

Uma pesquisa realizada por D’Aláscio et al. (2014) que incluía 84 trabalhadores de 34 postos de revenda de combustível a varejo da Macrorregião Sul de Santa Catarina, com o foco em demonstrar as condições do ambiente e o estado de saúde desses trabalhadores, buscou associar os hábitos laborais e os sintomas de intoxicação por benzeno informados pelos mesmos.

Ainda viram que o benzeno é um hidrocarboneto aromático que compõe os combustíveis e tem uma presença praticamente ubíqua no meio ambiente, variando apenas sua concentração. A intoxicação por benzeno, em sua forma aguda, acomete especialmente o sistema nervoso central e em altos níveis pode ser letal. Na forma crônica, está comprovadamente associada à ocorrência de leucemia mieloide aguda e leucemia linfocítica crônica.

Sendo assim, a pesquisa dos autores citados anteriormente apresenta um resultado negativo quanto ao benzeno, relacionado à saúde do trabalhador. Houve associação entre os hábitos ocupacionais que aumentam a exposição ao benzeno e a prevalência de sintomas compatíveis com intoxicação por benzeno. Mais de $81 \%$ dos trabalhadores estudados relataram não ter qualquer acompanhamento médico periódico ou monitoramento hematológico exigido pela legislação, além de não possuírem qualquer treinamento necessário ou equipamentos de proteção para exercer sua profissão com segurança.

D’Aláscio et al. (2014) afirmam também que este ofício está interligado à formação de lesões à saúde a começar de Hipócrates. Os problemas ocasionados por origem química, como o evento que acontece nas pneumoconioses dos colaboradores da exploração mineral, é documentadamente o mais simbólico.

A fabricação e os processos produtivos mais complexos, em especial os derivados da remoção e geração provenientes do petróleo, apresentaram uma quantidade de maior importância dos trabalhadores a recentes agentes químicos com grande capacidade de lesões a saúde progressivamente de maior complexidade. Além dos danos profundos, os causadores 
químicos preocupam gradativamente os resultados permanentes, em especial apresentando efeitos carcinogênicos confirmados.

A apresentação desses fatores cancerígenos é um assunto considerável no campo das organizações de saúde, já que a preservação à saúde dos colaboradores corresponde a umas obrigações legais, e por essa razão tratamentos disciplinares regulatórios possam se reunir para maior eficácia.

O ministério do trabalhado e emprego tem se dedicado em regimentar a troca de tal substância no método de fabricação do álcool anidro, nas metalurgias entre outros processos de fabricação na situação em que tal transformação possa ser ocasionada. Esse processo se deu devido à agência internacional de pesquisas a respeito do câncer, em 1982, reconhecer o Benzeno como cancerígeno (BRASIL, 1997).

A absorção do Benzeno acontece maiormente através da aspiração do mesmo na forma de vapor, depois através da pele e contato com a sua forma líquida, enfatizando que este composto está em vários lugares no ambiente urbano ao mesmo tempo alterando apenas sua concentração de acordo com o local examinado.

Os fenômenos por intoxicação por benzeno podem estar relacionados à alteração na respiração, no sangue, na medula óssea entre outros.

Em relação à respiração temos: dispneia, xerostomia e rinite alérgica. A intoxicação relacionada ao sistema nervoso central abrange sonolência, cefaleia, vertigem e tremores. Junto a mutações hematológicas periféricas da exposição ao benzeno, pode-se constatar anemia, leucopenia, linfocitopenia e trombocitopenia, doenças que se predispõem a uma sequência de alterações (D’ALASCIO et al., 2014).

\section{PROCEDIMENTOS METODOLÓGICOS}

Para a realização deste artigo, foi realizada uma pesquisa bibliográfica, baseada nos conceitos de segurança e qualidade de saúde no trabalho de frentista, para tal foi necessário pensar no elemento "benzeno", um produto que o frentista tem muito contato, para entender seus malefícios para a saúde do profissional.

O benzeno em altas concentrações é uma substância muito contaminante para as mucosas (olho, nariz e boca).

Segundo Juras (2005 apud LAUXEN, 2016) a inalação ou ingestão dos vapores dos combustíveis que contem o benzeno, causa tonteira, dor de cabeça, sonolência, náusea e 


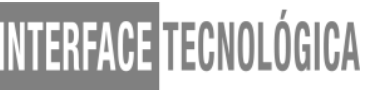

confusão. A aspiração desse produto nos pulmões pode levar a pessoa a ter pneumonia química, que pode ser fatal. A ingestão causa espasmos abdominais.

Os principais autores que abordam essa temática são D’Aláscio, Ferreira e Freire. Foi possível com essas leituras, que a segurança no trabalho do frentista focando na sua saúde, é primordial para a empresa e para o funcionário.

\section{RESULTADOS E DISCUSSÃO}

Nos postos de abastecimentos de combustíveis há muitos riscos, devido pelo contato com produtos periculosos, exercer diversas atividades, contracenar com um grande número de pessoas, além da probabilidade de assaltos e até mesmo atropelados.

Com isso, os colaboradores no geral devem tomar devidos cuidados para que todos os riscos sejam amenizados e eliminados do local de trabalho. No entanto, os empregadores devem investir na saúde e segurança do empregado, pois desde as décadas de 50 e 60 os funcionários têm ganhado mais forças quanto a qualidade de vida no trabalho, e isso ajuda até mesmo a empresa para que o colaborador não venha acarretar atestados médicos ou ate mesmo afastamento por invalidez.

\section{CONCLUSÃO}

Constatamos que por mais que seja investido em EPIs e segurança, o risco sempre estará lá devido à falta de treinamento dos profissionais, pouco visto em trabalhos e pesquisas, empregadores capacitando funcionários através de palestras, cursos e orientações que inibem as práticas habituais como cheirar tampa de combustíveis, limpar resíduos apenas com estopas e flanelas sem luvas o que não evita o contato com a pele entre outros.

Tais práticas são altamente prejudiciais à saúde, devido isso, sugerimos do nosso ponto de vista a punição do empregador ao funcionário, a fim de ser severo na prática de sua função, relacionada à vitalidade do próprio colaborador o que leva com total rigidez o aumento da segurança física do funcionário. 


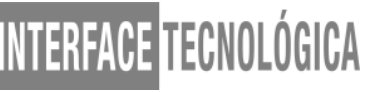

\section{REFERÊNCIAS}

BRASIL. Ministério do Trabalho e Emprego. Acordo Benzeno, de 1 de janeiro de 1997, Comissão Nacional Permanente do Benzeno, da Segurança e Saúde no Trabalho [Internet], 1997. Disponível em: <http://www2.mte.gov.br/seg_sau/comissoes_benzeno_acordo.asp.>. Acessado em: 28 nov. 2018.

D'ALÁSCIO et al. Sintomas relacionados à exposição ocupacional ao benzeno e hábitos ocupacionais em trabalhadores de postos de revenda de combustíveis a varejo na região sul de Santa Catarina. Rev Bras Med Trab. 2014; 12(1): 21-9.

FERREIRA, M. C; FREIRE, O. N. Cargas de trabalho e rotatividade na função de frentista. In: Rev. adm. contemp. vol.5 no.2 Curitiba May/Aug. 2001. Disponível em http://www.scielo.br/scielo.php?script=sci_arttext\&pid=S1415-65552001000200009 Acesso em 05 out 2018.

GUAPORÉ. EPIs para postos de combustíveis: fique atento! Disponível em https://www.guaporeprotecao.com.br/epis-para-posto-de-combustivel-fique-atento/ Acesso 28 set 2018 .

MAIA, T. S. T; MAIA, F. S. Qualidade de vida no trabalho e aspectos ergonômicos na função de frentista. In: XXX Encontro Nacional de Engenharia de Produção. São Carlos, SP, Brasil 12 a 15 de outubro de 2010.

ROCHA et al. Utilização de equipamentos de proteção individual por frentistas de postos de combustíveis: contribuição da enfermagem. In: Tex to Contexto Enferm, Florianópolis, 2014, Jan-Mar; 23(1): 193-202.

LAUXEN, D. H. Redução da exposição a compostos orgânicos voláteis no abastecimento de veículos: Estudo de caso avaliando o posicionamento do trabalhador. São Leopoldo: UNISINOS, 2016, 23 p. 